\title{
Studying Developed Countries' Experiences in the Development of Organic Fruits and Vegetables Market
}

\author{
Samariddin Berdiev (Tashkent State University of Economics, Uzbekistan)
}

\begin{abstract}
There is a rapid increase in organic fruit and vegetables worldwide as well as a rapidly growing potential of organic markets in developing countries such as Eurasian countries. Fruits and vegetables of Uzbek are one of the popular with taste and vitamins in the world, but the Uzbek market of organic food products have not been formed yet, to my knowledge there is no any literature regarding the topic in Uzbekistan. That is why the aim of the article is to explore the development of organic fruits and vegetable market in world's developed and Eurasian countries. Additionally, the Uzbek peoples' willingness-to-pay (WTP) and their expectations with regards to organic fruits and vegetables were investigated.
\end{abstract}

\section{Introduction.}

The increase in the chemicalization of agriculture in second half of the twentieth century led to a significant increase in yields cultures and productivity of animals. In this regard, countries with intensively developing agricultural production significantly increased the supply of food. The negative side of this process was the contamination of the crop products produced by nitrates and pesticides, and livestock products - hormones and antibiotics. The world agro-food market reacted to this by a significant increase in demand for organic products in developed countries, which began in the 90 s of the XX century and continues to this day. At present, developed countries (USA, Germany, France, etc.) provide the greatest demand for organic products, and in the formation of the proposal, along with Australia, the United States and the EU countries, developing countries play an increasing role: Argentina, Brazil, China and Uruguay.

The Uzbek market by imported some kind of organic products, because we have not legislation, and modern laboratory for produce organic products (but we have foods which called "farm," natural "products). Moreover, population of Uzbekistan does not know means organic and what is difference between organic and conventional foods. Organic agriculture, organic market and organic products are a new words and new sector in Uzbekistan, but it is one of the global, essential and developing sector in the world. For instance, last 3 decades the demand for organic products significantly increase as people become more health and environmentally conscious. According to the International Federation of Organic Agriculture Movements (IFOAM), about 50.9 million hectares of land were managed organically by 2.4 million producers who produced 81.6 billion dollars in 179 countries in 2015 . This continuous uplifting of increase creates immense possibility for developing countries where agriculture is the main livelihood. Organic farming can alleviate poverty as farmers get the premium price for their products. However, insufficient input and a lack of capital, training and awareness hinder the growth of organic cultivation in developing countries (Helga Willer and Julia Lernoud, 2017).

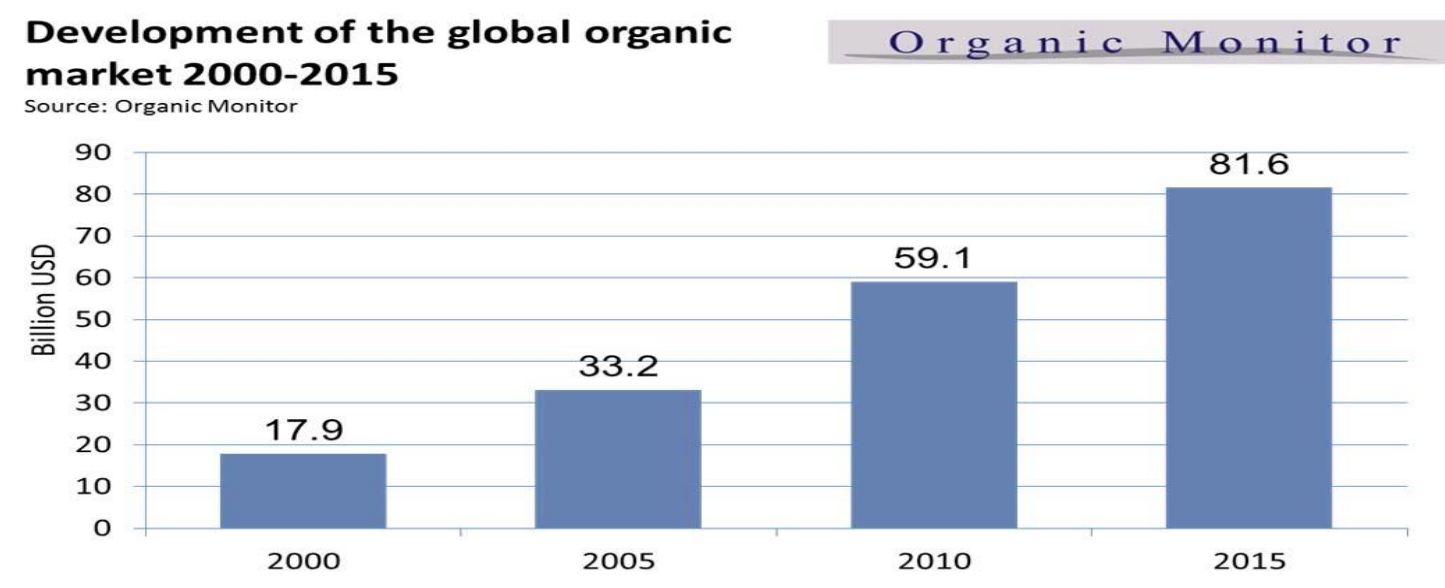

Figure 1. Development of the Global Organic Market 2000-20015. Source: Organic Monitor. 


\section{Development of the number of countries with data on organic agriculture \\ Source: FiBL-IFOAM-SOEL-Surveys 1999-2017}

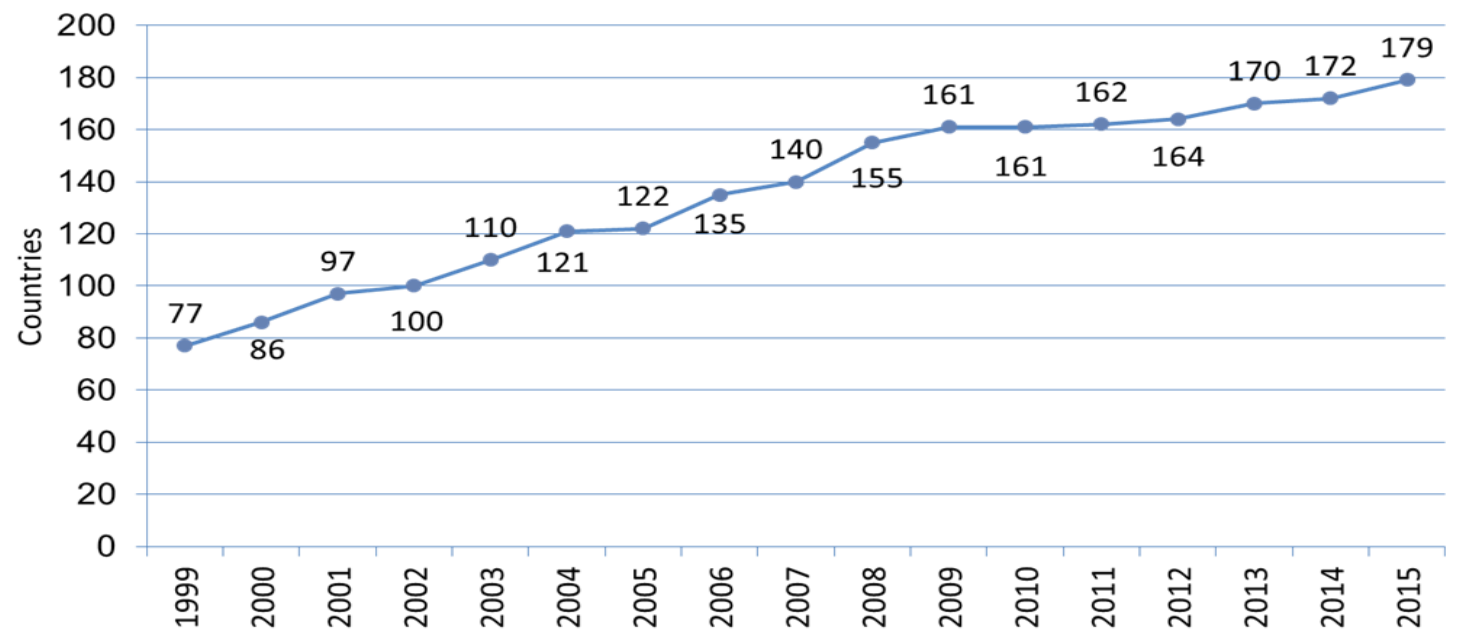

Figure 2. Development of the Number of Countries with Data on Organic Agriculture. Source: FIBL-IFOAVSOEL-Surveys 1999-2017.

\section{Why This Study Important and Relevance for Uzbekistan?}

Firstly, day by day products of genetically modified organism and conventional (which used so much artificial pesticides) is taking possession in Uzbek products markets and approximately 40 percent products of supermarkets are GMO. Some international organizations do not allow to the younger generation due to the adverse effects of using GMO products. According to the information of "Uzstandart" agency of Uzbekistan, in the large retail chains of Tashkent, the agency "Uzstandart" found a batch of poor-quality food products. The agency warned about the dangers of using these products for health. In particular, according to the results of the inspection, the chemical and biological laboratory of the Republican Test and Certification Center for the 9 months (2017) revealed 232 cases of defective food products. It is a very dangerous for us that is why Government should develop and support organic products instead of GMO and conventional products.

Secondly, the independence of the Republic of Uzbekistan, which is one of the global problem to ensure the food safety. Nowadays, the number of the country's population about 32.5 million and this indicate will be approximately 50 million in 2050. Indeed, growth of population is a good result but this can lead to food shortages. As we know, the land and resources are limited, but human needs will continually increase. We should use effectively existing resources in new and innovative ideas and technologies to create the primary needs of the people, the food products to expanding the quantity and quality of production such as organic products (S.Berdiev, 2017).

Finally, President of Uzbekistan Shavkat Mirziyoev signed a decree "On action strategy on further developing of Uzbekistan" on 7 February 2017. The action strategy on five priority directions on development of Uzbekistan is designed for 2017-2021. One of the main task is ".deepening of structural reforms and dynamic development of agricultural production, further strengthening of the country's food security, expansion of production of environmentally friendly products, a significant increase in the export potential of the agricultural sector". The task also shows that relevance of this topic.

Literature review. As the Uzbek market of organic agro-food products have not formed yet, that is why the nobody has not done research about this topic in Uzbekistan. As a rule, the foreign authors considered the individual components and characteristics of this market. Thus, the production aspect is presented in the works devoted to organic farming. The development of this direction began by scientists in the 1920s. Among the foreign researchers, the greatest contribution was made by R. Steiner, Yves Balfour, Lord Northbound, A. Howard, M. Fukuoka, among the Soviet researchers - V.R. Williams. Foreign experience in the formation and development of organic markets is presented mainly in national reports on this subject and in foreign periodicals. In this direction work: B. Beck, M. Kleinmann, N. Prokopchik, J. Paul, T. Richter, D. Matera, I. Rose and others. The methodological basis of the study is a systematic analysis of the theoretical and practical aspects of the formation of the market of organic fruit-vegetables products. Along with this information basis of the work was made up of articles in periodicals of domestic economists and materials posted on Web-pages of leading scientific institutions 
in the Internet. The empirical base of the research included materials of the State Statistics Committee of the Republic of Uzbekistan, the Ministry of Agriculture and Water Resources of the Republic of Uzbekistan, "Uzbek food holding" holding company, as well as actual materials of Argo industrial organizations of Uzbekistan.

The idea of organic farming is not new for the Republic of Uzbekistan as the country has its historical trends of traditional low-input agricultural practices. Consequently, the age-old culture of the traditional vegetable farming and horticulture in Uzbekistan were originally based on the principles of biological farming with the use of organic fertilizers and without the use of genetically modifying technology. Uzbekistan has a strategy to develop sustainable resource management and implement agro-food quality assurance systems and to increase access to international markets. According to the figures, organic products are already marketed. Uzbekistan produced 1000 tons of organic raisins, 500 tons of organic dried plum and 3000 tons of organic dried apricots in 2016 and exported to Germany and the United States of America (Figure 3) (Aziz Nurbekov, et. al, 2018).

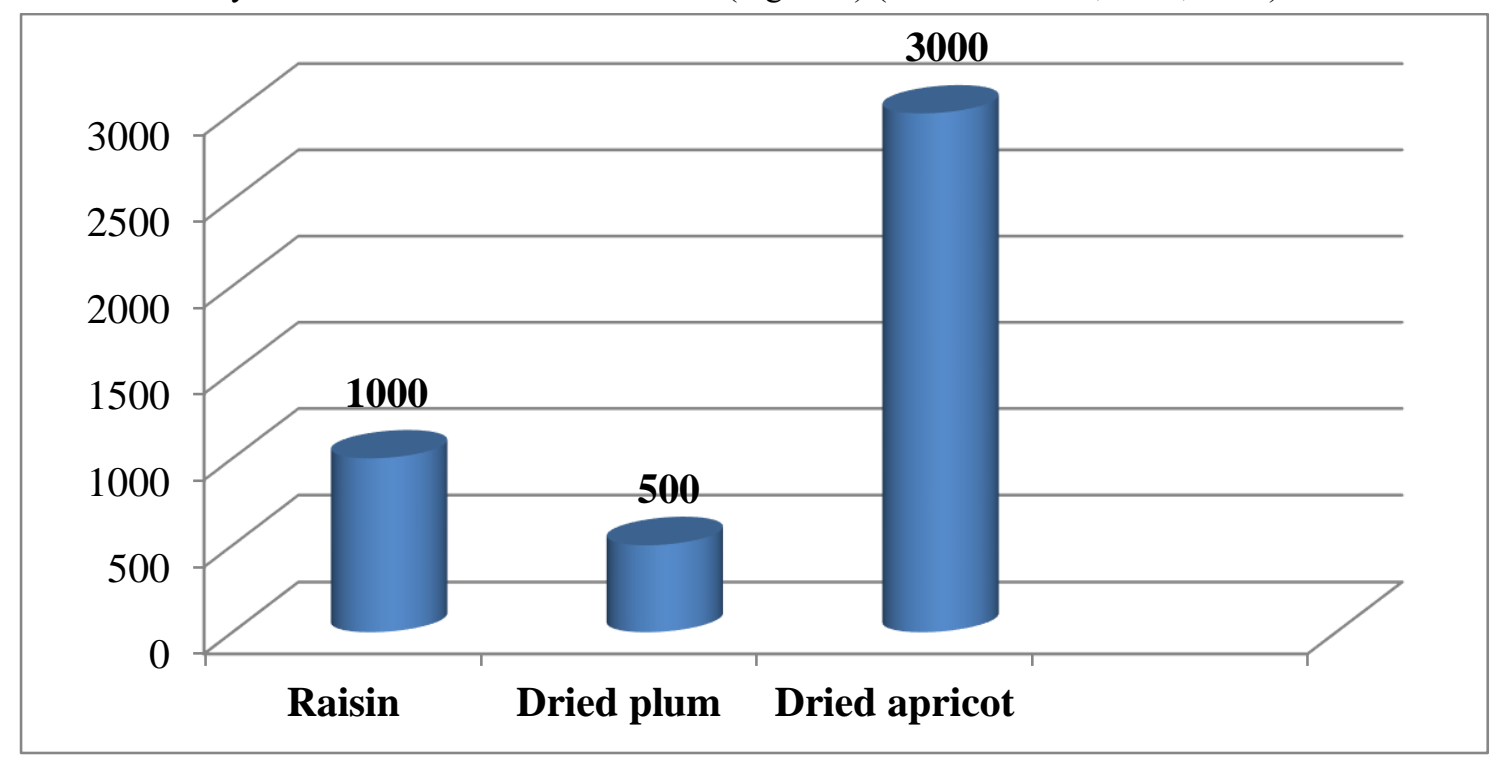

Figure 3. Organic Raisin, Dried Plum and Dried Apricot Production in Uzbekistan (2016)

It is important to note that Uzbekistan is currently increasing production of fresh vegetable and fruits as well as dried produce for the export markets. Russian bazars, which lose market share to supermarkets very quickly, are the major market for Uzbekistan's vegetable and fruits now. Unless serious fundamental policy changes are made in Uzbekistan, this situation is unlikely to change. Currently, there is no local market for organic food in Uzbekistan. Primarily, this is due to the fact that, consumers are not fully informed about organic products. Uzbekistan has drafted law on organic agriculture and is going to adopt to set up a legal framework that regulates relations in the field of organic agriculture and organic food production as well as forms and methods of control over the production and labeling of such products. Another serious challenge that hampers the development of organic farming and organic food production are low level of awareness of most market players about the difference between organic farming enterprises, dehkan farms and their products and traditional farming enterprises and dehkan farms (Aziz Nurbekov, et. al, 2018).

Organic and fair trade certified commodities in Uzbekistan (peanuts, chickpeas, cherries, bee berries, mulberries, almonds, flax seed, sesame seeds) have been produced as export oriented and on a contracting base, there seems to be more marketing opportunities also in the domestic market in the future. The price of organic fruit-vegetables products, exported from Uzbekistan, varies largely, but generally ranges from 20 to 30 percent above the price for conventional products, but can sometimes reach 100 percent (Personal communication with private organic product exporter in Uzbekistan). If the organic system being established in Uzbekistan is introduced to the world organic community, and organic fruit-vegetables products of Uzbekistan origin are presented in international fairs and expos, more companies will raise their interested in making contracts with Uzbek farmers.

\section{Conclusion}

The domestic organic fruit - vegetable market in Uzbekistan is in its infancy. The lack of organic legislation and promotion of standards, as well as the lack of support impede its growth. Reliable information on principles and mechanisms of organics, on bio-products on the scale of the country, is absent, that contributes to the development of green washing. Prices for organic in Uzbekistan, in contrast to United States and European countries, are greatly overstated. That is why domestic demand for organic, as well as domestic organic market in Uzbekistan has not yet been formed. Demand for organic produce is rapidly increasing (worldwide by 3\% each year), hence the necessity to stimulate its global production. Because of its agricultural tradition, genetic resources, workforce as 
well as adequate environmental conditions, Uzbekistan represents a huge opportunity to contribute to global agricultural production expansion. However, some very important aspects still need to be addressed, such as international quality standards implementation, offsetting the higher cost of organic production and certification for producers and consumers and effectively market organic production.

\section{References}

- Action plan II: Developments in organic farming. English summary [Electronic source]. - The Danish Ministry of Food, Agriculture and Fisheries, The Danish Directorate for Development, January 1999. System requirements: Adobe Reader. -URL: http://www.ecoweb.dk/ftp/dokumenter/action-organic.pdf (date of treatment: 20.10. 2010).

- Aziz Nurbekov, et. al, 2018. Organic agriculture in Uzbekistan: status, practices and prospects. Food and Agriculture Organization of the United Nations, Tashkent.

- Council Regulation (EC) No 8 34/2007 of 28 June 207 on organic production and labeling of organic products and repealing Regulation (EEC) No 2092/91 // Official Journal of the European Union. 20.07.2007.

- Ministry of Justice of the Republic of Uzbekistan, 2018. 2017-the year of sweeping reforms. Tashkent,Adolat

- OECD, 2017. Information Technology Outlook 2015, www.oecd.org/sti/interneteconomy

- Organic Food Production Act of 1990 [Electronic source]. - 10.2005. -

- Organic products: marketing study [Electronic source]. - 15.04.2009. URL:http:/www.agracultura.org/en/marketing/organic-productsmarketing-study.html (date of treatment: 16.10.2009).

- $\quad$ S.Berdiev, 2016. Food security in transition economies: the case of Uzbekistan. "3 rd International open conference on business and public administration. 6-17 April 2016. Athens. 37-43.

- S.Berdiev, 2017. Development of the innovative food industry in the conditions of ensuring food security // Bulletin of science and practice. Electron. journal. 2017. №8 (21). C. 201-207. URL: http://www.bulletennauki.com/berdiev (date of treatment 15.08.2017). DOI:10.5281/zenodo.842918.

- The national legislation database of the Republc of Uzbekistan, 2017. www.lex.uz

- The Organic Market in Europe [Electronic source]. - SIPPO and FiBL, - 05.2011. - System requirements: Adobe Reader. - URL: http://www.sippo.ch/internet/ oases/en/ home/import/publications/food. ContentSlot98296-ItemList-61735 .

- Willer H, 2017. The world of organic agriculture statistics and emerging trends 2017. Research institute of organic agriculture FIBL and IFOAM Organics International. http://www.organicworld.net/yearbook/yearbook-2017.html. 